\title{
Artigos
}

\section{Os desafios da formação problematizadora para profissionais de saúde em um programa de residência multiprofissional}

\author{
Challenges of a questioning education to health professionals in a \\ multiprofessional residency program (abstract: p. 11)
}

Los desafíos de la formación problematizadora para profesionales de salud en un programa de residencia multiprofesional (resumen: p. 11)

\author{
Maria Clara Santana Maroja ${ }^{(a)}$ \\ <claramaroja@gmail.com> \\ José Jailson de Almeida Júnior(b) \\ <jailsonjrn@gmail.com> \\ Claudianny Amorim Noronha(c) \\ <cnoronha.ufrn@gmail.com> (iD
}

\author{
(a) Pós-graduanda do Programa de \\ Pós-Graduação em Educação \\ (Doutorado), Universidade \\ Federal do Rio Grande do Norte \\ (UFRN). Cidade Universitária, \\ $\mathrm{s} / \mathrm{n}^{\circ}$, Lagoa Nova. Natal, RN, \\ Brasil. 59070-405. \\ (b) Faculdade de Ciências da \\ Saúde do Trairi, UFRN. Natal, \\ RN, Brasil. \\ (c) Programa de Pós-Graduação \\ em Educação, UFRN. Natal, \\ RN, Brasil.
}

Pretende-se refletir sobre as dificuldades e potencialidades na aplicação da Educação Problematizadora em um programa de residência multiprofissional em Saúde, na perspectiva do fortalecimento do Sistema Único de Saúde (SUS) por meio da qualificação das ações pedagógicas nesse campo. Trata-se de uma pesquisa avaliativa, participativa e com abordagem qualitativa, do tipo Estudo de Caso, realizada em um programa de residência multiprofissional em Saúde Mental. Entre os elementos pedagógicos freireanos identificados, destaca-se o ciclo retroalimentado ação-reflexão-ação - capaz de potencializar o próprio processo educativo -, enquanto as limitações à proposta educacional problematizadora apresentaram-se relacionadas às contradições com os modelos formativos e práticos vigentes no campo da saúde. Uma melhor apropriação dos fundamentos educacionais que sustentam as residências multiprofissionais em Saúde, por parte de tutores, preceptores e residentes, é capaz de potencializar o processo de ensino-aprendizagem para os trabalhadores do SUS.

Palavras-chave: Formação de profissionais de saúde. Problematização. Paulo Freire.

Maroja MCS, Júnior JJA, Noronha CA. Os desafios da formação problematizadora para profissionais de saúde em um programa de residência multiprofissional. Interface (Botucatu). 2020; 24: e180616. https://doi.org/10.1590/Interface.180616 


\section{Introdução}

Sustentadas pela compreensão das relações políticas e humanísticas que conduzem a interação ensino-serviço-comunidade, as residências multiprofissionais em Saúde surgiram como uma aventura de poucos e, nos anos 2000, configuraram-se como estratégia nacional de formação de profissionais para o SUS brasileiro. Em verdade, ainda hoje as residências multiprofissionais são consideradas uma proposta curricular inovadora no ensino em saúde, por apresentar uma estrutura pedagógica fundamentada na problematização da realidade dos serviços de saúde. Nessa modalidade de pós-graduação lato sensu, as atividades práticas e teórico-práticas correspondem a $80 \%$ da carga horária total do curso, sendo desenvolvidas com base no trabalho em equipe multiprofissional e sob a orientação de tutores e preceptores, que são, respectivamente, docentes do programa e profissionais dos serviços de saúde, designados a essa atribuição. Isso faz do processo de ensino-aprendizagem nas residências um mergulho profundo na realidade da saúde das comunidades, capaz de produzir não só conhecimentos científicos aos residentes, mas também transformações de si e do mundo ${ }^{1,2}$.

As residências multiprofissionais em Saúde são fomentadas pela Política Nacional de Educação Permanente em Saúde, segundo a qual a dinâmica de aprendizagem no trabalho deve ser construída pelos diferentes atores envolvidos, ganhando sentido por estar alinhada à realidade dos trabalhadores. Na perspectiva dessa política, os profissionais da saúde são considerados como agentes de mudanças; e o processo educativo compreendido como produção de sujeitos críticos e reflexivos sobre a realidade ${ }^{3}$.

A concepção de formação apontada na Política Nacional de Educação Permanente em Saúde explicita claramente, em seus documentos normativos, a intencionalidade de uma educação coerente com a Educação Problematizadora defendida por Paulo Freire - embora essas relaçóes não estejam devidamente referenciadas. Percebem-se diretamente as ideias do pedagogo na afirmação de que o ser humano não pode ser compreendido fora de seu contexto: ele é o sujeito de sua própria formação e se desenvolve por meio da reflexão sobre seu lugar no mundo, sua realidade e suas vivências ${ }^{3,4}$.

É, portanto, no trabalho de aprofundamento das bases pedagógicas que sustentam as residências multiprofissionais em Saúde e na defesa das intercessões entre essa proposta de formação em saúde e a Pedagogia Problematizadora de Freire que se assentam os esforços para a escrita deste artigo.

Nesse sentido, serão discutidas neste estudo algumas das dificuldades e das potencialidades na aplicação da Educação Problematizadora em um programa de residência multiprofissional em Saúde. Não se pretende somente descrever a experiência pedagógica lócus da pesquisa, ou compará-la a outras realidades educacionais semelhantes, mas também contribuir com uma reflexão crítica e dialética para o fortalecimento do SUS por meio da qualificação das ações pedagógicas no ensino em saúde.

\section{Métodos}

Trata-se de uma pesquisa avaliativa, participativa e com abordagem qualitativa, do tipo estudo de caso único. O lócus de estudo escolhido foi o programa de residência multiprofissional em Saúde Mental, oferecido pela Universidade Federal da Paraíba, cujo projeto de curso - submetido em 2015 à aprovação pela Coordenação Geral de 
Residências Multiprofissionais em Saúde, Ministério da Educação e Cultura - estabelece a metodologia de ensino baseada na Pedagogia Problematizadora de Paulo Freire.

Foram aplicadas entrevistas individuais semiestruturadas aos tutores (7) e preceptores (7), bem como dois encontros de grupo focal com vinte residentes (tendo sido o primeiro encontro realizado no mês de ingresso da turma iniciante no ano de 2017 - março - e o segundo, com os mesmos participantes, no fim do primeiro ano de curso - dezembro). Os tutores e preceptores foram selecionados a partir de um único critério de exclusão: tempo de atuação no programa inferior a um ano. Todos os tutores e preceptores aptos a participar da pesquisa foram entrevistados.

O roteiro para aplicação do primeiro encontro de grupo focal com os residentes contemplou questôes distribuídas nos seguintes eixos temáticos: 1) Processos de capacitação e 2) Concepções sobre problematização nas práticas profissionais em saúde. Quanto ao roteiro para aplicação do segundo grupo focal, este foi construído em um eixo temático único: 3) Processos de trabalho e concepções sobre problematização nas práticas profissionais em saúde. Esses três eixos temáticos foram contemplados também nos roteiros para entrevistas semiestruturadas com tutores e preceptores, acrescidos do eixo 4) Percepçôes sobre as práticas profissionais dos residentes. Os instrumentos para as entrevistas individuais foram validados por meio da aplicação dessa técnica a tutores e preceptores de outros dois programas de residência multiprofissional em Saúde. Observou-se nessa ocasiáo se houve compreensão do conteúdo por parte dos entrevistados, se a ordem das questôes obedecia a uma lógica sem indução de respostas e se todos os objetivos haviam sido contemplados.

Todas as técnicas para coleta de dados foram executadas pela pesquisadora autora da tese de doutorado que originou o presente artigo. As entrevistas foram gravadas por meio de gravador digital de voz e transcritas na íntegra, utilizando-se codinomes para preservar a identidade dos participantes.

Os dados coletados foram então analisados seguindo-se as etapas propostas por Bardin ${ }^{5}$ para a Análise de Conteúdo:

1) Pré-análise - leitura do material e organização dos dados segundo os eixos temáticos e sujeitos - residentes, tutores e preceptores.

2) Exploração do material - classificação dos dados segundo duas categorias de análise previamente estabelecidas: a) Elementos curriculares freireanos nas práticas pedagógicas(identificação desses elementos, suas limitações e seus fatores facilitadores) e b) Práticas problematizadoras nas atividades dos residentes nos serviços de saúde (identificação dessas práticas, suas limitações, fatores facilitadores, avanços ao longo do curso, suas relações com as ideias instituintes do SUS e associaçóes com os elementos curriculares freireanos).

3) Tratamento dos resultados e interpretação - estabelecimento de articulaçôes entre os dados coletados e os referenciais teóricos, do qual emergiu o tópico que intitula o presente artigo.

O estudo foi aprovado pelo Comitê de Ética em Pesquisa do Instituto Federal de Educação, Ciência e Tecnologia da Paraíba, sob o protocolo no 65311717.6.0000.5185, e todos os participantes assinaram o Termo de Consentimento Livre e Esclarecido. 


\section{Resultados e discussão}

A dinâmica pedagógica do curso, cenário de estudo, inicia-se com a inserção dos residentes nas rotinas dos serviços públicos de saúde, quando são orientados a reconhecer e compreender aspectos referentes ao funcionamento de cada unidade - a exemplo das etapas do fluxo de atendimento, estrutura física, relaçôes interprofissionais e questôes relativas à gestão. Nesse primeiro momento, os residentes também são estimulados a observar as características e necessidades gerais do público-alvo assistido, bem como da comunidade circunscrita ao serviço. À medida que os residentes se envolvem com as atribuiçốes específicas de cada profissão, em sala de aula são aprofundadas temáticas do conhecimento científico, além de questôes ligadas ao trabalho multiprofissional e às subjetividades no atendimento em saúde, a partir das experiências vivenciadas nos cenários de prática. A fala a seguir sintetiza as bases para construção dos conteúdos a serem trabalhados nos encontros de tutoria:

Eles [os residentes] chegam; nós fazemos um acolhimento inicial com eles, de colocar o que aconteceu. Depois desse momento, nós passamos pras discussóes durante a roda de conversa, se algo chamou mais atenção ou eles tão sentindo necessidade de um suporte maior. Durante a conversa eu vou dando algumas referências, e eles vão buscando também, construindo e trazendo já pra na outra tutoria a gente resgatar isso que ficou. A gente tá tentando colocar uma dinâmica com o trabalho de apropriação da profissão, da apropriação desses espaços de trabalho. (Tutor - LMTP)

O compromisso educacional com a realidade, nesse caso, é concebido a partir de um processo permanente de construção curricular, movimentado pela problematização das rotinas dos serviços de saúde mental, espaços nos quais os residentes buscam aperfeiçoamento e inserção profissional. Essa problematização é feita essencialmente pelos próprios residentes, que levam dos serviços para os encontros semanais de tutoria e preceptoria os temas significativos que conduzem o processo ensino-aprendizagem na universidade e nos próprios cenários de prática.

O conteúdo curricular na concepção da Educação Problematizadora deve ser construído com base no diálogo entre todos os atores envolvidos nesse processo - no caso da saúde, entre os alunos, professores, profissionais de saúde dos serviços e usuários. Emmerich et $\mathrm{al}^{6}$ defendem que o conteúdo curricular no contexto da saúde deve ser organizado a partir de situaçóes concretas e das demandas da sociedade, para que, partindo de problemas reais, o educando se sinta desafiado e busque uma resposta no campo do conhecimento, mas, sobretudo, no campo da prática resolutiva e transformadora.

Para tanto, é necessário que os educadores investiguem o universo temático dos residentes e que estes, por sua vez, investiguem o universo temático dos usuários dos serviços de saúde. É pertinente para essa compreensão - em especial por estar sendo aqui proposta a aplicação da pedagogia freireana ao ensino em saúde - a elucidação de Freire, quando este afirma que investigar o universo temático não significa compreender o homem como se fosse um objeto, peça anatômica, mas sim o seu pensamento-linguagem referido à realidade e os níveis de percepção que alcança dessa realidade 7 . 
Tal ideia, no processo formativo, diz respeito ao entendimento sobre as relaçóes dos residentes com o mundo profissional (as situações-problema encontradas e as açóes diante destas) e com aqueles que movimentam esse mundo (equipe prof issional, usuários do SUS, comunidade, etc). Quanto à investigação do universo temático dos assistidos, esta se aplica à compreensão dos fatores intervenientes no processo saúde-doença de cada indivíduo (características socioeconômicas, culturais, epistemológicas, entre outras) e da forma como esse indivíduo enxerga a sua realidade.

Sendo assim, os docentes e tutores do programa de residência têm dupla tarefa: problematizar e, sobretudo, ensinar os princípios e métodos dessa prática aos seus alunos. A segunda tarefa não se faz necessariamente separada da primeira, mas o exercício de problematizar é incorporado às práticas profissionais dos residentes, principalmente como consequência da experiência com essa pedagogia dentro da universidade. Segundo alguns depoimentos de tutores, essa ingerência das açôes pedagógicas sobre os processos de trabalho dos residentes é percebida em atitudes como a exemplificada a seguir:

Eu acho que a gente já percebe isso em algumas falas deles mesmo: "Olhe, surgiu uma problemática”. Então o serviço não tava nem aí - o que foi que a equipe de residentes fez? Se reuniu duas horas dentro do serviço pra discutir o caso: como era que a gente ia resolver, a quem acessar. Então eu acho que isso aí já é fruto desse processo, do que é feito aqui dentro [...]. (Tutor - MMQN)

O currículo que projeta em seus conteúdos e métodos a realidade dos educandos vai muito além de tornar o ambiente educacional mais agradável ou interessante para os seus alunos. Também não deve limitar-se ao pensamento crítico sobre as situaçốes-limite encontradas no contexto desses sujeitos. Deve-se pensar o papel da universidade naquela sociedade naquele momento e trabalhar o conhecimento em cenários reais e plurais da práxis, de modo a proporcionar novas reflexóes e açóes.

Freire explica que, assim como não há homem sem mundo, não pode haver reflexão e ação fora da relação homem-realidade. Essa relação implica a transformação do mundo, cujo produto, por sua vez, condiciona ambas: ação e reflexão ${ }^{8}$.

A reflexão crítica proposta pela concepção problematizadora da educação concerne à realidade na qual os educandos estão inseridos e, dessa forma, também diz respeito às próprias açóes do processo ensino-aprendizagem, vinculando prática e teoria em um movimento dialético de ação-reflexão-ação, na perspectiva transformadora' ${ }^{9}$.

Nesse movimento, as próprias práticas pedagógicas também são retroalimentadas pela reflexão sobre elas mesmas. Além disso, também se entende que o conhecimento somente se constrói na ação coletiva. O aprender e o ensinar, nessa perspectiva, incorporam outros significados, uma vez que começam a ser compreendidos como atividades interdependentes de ação-reflexão-ação, agregando-se também a dimensão do engajamento em face de um projeto coletivo de interpretação da realidade ${ }^{10}$.

Como exemplo dessa cinesia entre ação e reflexão dentro do processo pedagógico, foi observada a experiência da atividade intitulada "Café com prosa", que surgiu a partir de uma ideia dos residentes incorporada às atividades curriculares do curso e lócus da pesquisa, que acontecem dentro da universidade, e que posteriormente passou a ser adotada 
também em alguns serviços. "Café com prosa" consiste em rodas de conversa realizadas mensalmente com o objetivo de trazer as equipes de saúde para o espaço acadêmico e discutir, junto com os residentes, tutores, docentes e coordenadores do programa, sobre problemas que tensionam a realização das atividades nos serviços de saúde.

Deve-se considerar que esse tipo de movimento pedagógico, assim como toda a dinâmica de ensino-aprendizagem proposta pelo programa de residência em estudo, pode ser facilitado pela lógica de funcionamento em alguns serviços de saúde, também baseada na prática problematizadora, que considera o contexto de vida de cada usuário para o tratamento da sua saúde, sob a perspectiva do trabalho coletivo e multiprofissional. Contudo, essa prática não é observada em muitos dos cenários, em que os residentes se deparam com rotinas tão estreitamente pré-determinadas, que parecem limitar a atenção à saúde a um atendimento clínico e hospitalocêntrico, desconectado da complexidade de cada indivíduo e da multifatorialidade causadora das patologias. As falas de preceptores a seguir representam essas divergências na dinâmica de atendimento nos serviços:

Aqui é tudo um processo de construção no coletivo [...]. Então a gente trabalha muito reorganizando, reordenando, vendo quais as possibilidades, escutando, problematizando. A gente trabalha muito através de estudos de caso e aí a gente vai ressignificando como tá desenvolvendo as nossas atividades. (Preceptor-JOMD)

Hoje a gente já tem uma forma de trabalhar com a atenção farmacêutica. É olhar para o paciente enquanto farmacêutico, contribuindo com que medicamento tá tomando, se é só medicamentoso o tratamento. A questão às vezes é que, por exemplo, aqui no hospital a gente ainda não é forte em linha de cuidado, em questão de trabalhar multiprofissional, aí quando os meninos vêm pra cá, eles sentem o impacto por causa do ambiente do hospital, aí não funciona muito. (Preceptor - RADMS)

Lidar com as diferenças nas linhas de atenção à saúde, nas quais ainda se faz dominante o modelo técnico-linear de atendimento, significa necessariamente lidar também com as divergências nos processos formativos em saúde, também marcados pela tradição biologicista. Prova disso é o fato de haver, no início do curso, um estranhamento, entre os educandos, diante da proposta pedagógica da residência. Os depoimentos dos tutores mostram haver certa resistência dos alunos a esse tipo de metodologia, expressada quase que exclusivamente pelos residentes recém-ingressos - os mesmos que, é importante salientar, revelam também desconhecimento sobre a pedagogia problematizadora. Para esses residentes, a dinâmica pedagógica proposta pelo curso parece incumbir aos alunos atribuiçôes inerentes aos professores, eximindo estes das responsabilidades de planejar e desenvolver as atividades curriculares, bem como de dar resolução às situaçôes-problema encontradas ao longo das experiências nos cenários de prática. A seguir, o depoimento de um tutor que revela esse fato, corroborado pela fala de um residente recém-ingresso no programa: 
Têm estudantes que gostam de metodologias ativas, têm estudantes que não gostam, gostam de estar só recebendo, têm estudantes que acham que isso aí (problematização) é pro professor não fazer nada, que é pra poder colocar a responsabilidade neles. (Tutor - ASLGL)

Eu não gosto dessa história de "abraço coletivo"... Prefiro ficar sentada, ouvindo o professor falar. (Residente - FM)

Nota-se, assim, que os princípios e métodos da Pedagogia Problematizadora precisam ser esclarecidos aos residentes - desde o momento em que ingressam no curso - não apenas para evitar concepçóes equivocadas a respeito dessa pedagogia, mas sobretudo para que os alunos alcancem, na prática cotidiana, os objetivos da proposta pedagógica.

Ademais, há também o medo de alunos e professores quando se trata de pôr em prática um tipo de educação que provoca criticamente suas consciências, embora não se fale abertamente sobre ele. Esse medo é discutido na fala do preceptor a seguir:

Não sei se a nossa formação... as pessoas têm dificuldade de abordar o novo, nem que seja para experimentar; de arriscar, né? Sair da zona de conforto não é algo que todo mundo topa, né? Todo mundo quer... "Não, eu vou fazer o que eu já faço, como meus professores me ensinaram. Eu só sei fazer assim”. Com medo de errar, né? (Preceptor - JRM)

As concepçôes sobre os bloqueios no caminho pedagógico, apesar de discutidas na década de 1980, permanecem vivas no contexto atual. Para os autores, esses entraves estariam mais relacionados aos riscos profissionais e políticos do que propriamente às dificuldades em experimentar. $\mathrm{O}$ conservadorismo impóe, aos estudantes, provas de aptidão, requisitos, individualismo e retorno ao básico. A ansiedade e a impaciência para conquistar o emprego fazem com que o estudante queira saber apenas como determinado curso lhe ajudará a desenvolver aptidóes para se inserir em um difícil mercado de trabalho. As escolas e faculdades doutrinam os educandos com provas e orientam-se por condutas repressivas ${ }^{11}$.

Seja o desconhecimento acerca de como se dá o processo ensino-aprendizagem baseado na problematização, seja o medo de arriscar a razão para a resistência dos alunos a esse tipo de pedagogia, o fato é que estamos tratando de uma proposta pedagógica ainda considerada inovadora, pouco adotada, sobretudo no ensino em saúde. Essas questôes são claramente percebidas pelos tutores, que notam também uma gradativa desconstrução das ideias errôneas sobre a problematização entre os residentes, na proporção em que estes se envolvem e se apropriam dos fundamentos e métodos pedagógicos. A seguir, tem-se uma das falas de tutores em que se identifica essa desconstrução:

Eu vejo que algumas pessoas chegam sem tá tão preparadas pra receber esse tipo de metodologia. E aí depois, com o passar das situaçôes, elas já vão ficando mais atentas pra isso. Alguns chegam esperando na tutoria que tenha aula e diz "Eu tive um caso de esquizofrenia" e espera que eu diga: "Ah! A esquizofrenia é as- 
sim, as características são essas, pra dar um diagnóstico de esquizofrenia é só com tanto tempo e tem que apresentar isso e isso". Não é minha proposta, porque isso ele vai conseguir se jogar no Google "características de esquizofrenia”. Eu acho que vai além disso a tutoria, tem que ir além disso. Ele [o residente] aprendeu assim, não teve vivência. Claro que tem $n$ situações, mas a maioria, eu vejo essa transformação, primeiro uma revoltazinha... "Ah não! Mas eu quero a aula, eu gosto". Precisa disso, não sei se até na ideia de reproduzir, não sei, mas depois que eles... Ai, quando eles começam a se apropriar, ai isso é deixado de lado, eles já não fazem mais tanta questão de aula. (Tutor LMTP)

Para constatarmos essas transformaçóes que ocorrem ao longo do curso, retomemos o depoimento do residente FM, anteriormente citado, que, no início da residência, referiu preferir o método convencional de aula expositiva e demonstrou não conhecer a pedagogia problematizadora, fazendo associações equivocadas. O mesmo aluno, após o primeiro ano de curso, reconheceu que as experiências na residência lhe proporcionaram aprendizagens que levaram à ampliação da sua visão de práticas profissionais, com destaque para o trabalho em equipe multidisciplinar:

Pra mim, a maior aprendizagem está sendo trabalhar em equipe, de verdade. Assim... porque já tive experiências profissionais como assistente social em saúde mental, mas a gente acaba, como profissional, se fechando um pouco no núcleo, no seu núcleo. Apesar de ter consultas, de ter reunião de equipe e tal, eu nunca tinha trabalhado tão intensamente assim, com pessoas com outras perspectivas. Foi nítido que eu tive um pouco de dificuldade no começo... Essa coisa de tu atender o usuário, entende? De uma forma multi, acho que é muito rico, muito interessante. Fazer uma escuta com uma pessoa da psicologia, uma [terapeuta ocupacional] TO, enfim, uma enfermeira. Isso só agrega eu acho também. Sair um pouco daquela... porque a gente acaba... a nossa formação acaba criando um “cabresto". (Residente FM)

É bem verdade que a metodologia problematizadora procura reorganizar a teoria e a prática de modo a romper com o modelo tradicional de ensinar e aprender. Em saúde, é tradicionalmente maior a preocupação com as tecnologias de diagnóstico e tratamento de enfermidades, em detrimento das estratégias de prevenção de agravos e promoção da saúde. Em uma exposição sistematizada das críticas ao modelo biologicista hegemônico, que tem conduzido a formação dos profissionais da saúde, Villardi et a ${ }^{12}$ atribuem a esse modelo características curriculares marcadas por disciplinas fragmentadas e centradas no conteúdo e no professor.

Para Emmerich e Fagundes, essa postura educativa tem sido observada, não só na formação profissional, mas também nos processos de trabalho nos serviços de saúde, mesmo tendo sido questionada nos últimos anos. O que se percebe são práticas desconectadas do contexto social da população, da escuta sensível do que os usuários dos serviços de saúde têm a dizer e da ação política no enfrentamento dos desafios do sistema ${ }^{6}$. 


\section{Considerações finais}

A análise do material empírico revelou quão inovadora, ainda, é considerada a modalidade de ensino das residências multiprofissionais em Saúde. Para tal comprovação, a legitimidade dos discursos daqueles que movimentam esses espaços educacionais forneceu alguns elementos, a exemplo das contradiçốes entre a prática problematizadora e os modelos formativos e práticos vigentes no campo da saúde. Nesse sentido, constatou-se uma significativa resistência, entre os educandos, à prática da problematização, especialmente os recém-ingressos, seja tal resistência causada pelo desconhecimento a respeito dessa pedagogia, seja pelos medos em arriscar uma formação que desperta a consciência crítica e a necessidade de transformação.

Deve-se esclarecer que, nesse contexto, não ocorre, na maioria das vezes, ação imediata de mudança de comportamento. Essa mudança só será percebida quando houver marcas da transformação do saber - o que não acontece rapidamente: elas vão surgindo em processos contínuos, na intermediação entre o saber científico instituído e o saber proveniente das experiências vivenciadas no mundo real ${ }^{13}$. Contudo, foi possível visualizar, durante o processo educativo lócus desse estudo, sinais do despertar da consciência crítica e do ímpeto de transformação da realidade em meio aos desdobramentos dos processos de trabalho dos residentes. Segundo Freire, essa tomada da consciência crítica inicia-se nas relaçôes do homem com o mundo e na reflexão sobre esse mesmo ato. Quando o homem compreende sua realidade, pode levantar hipóteses sobre o desafio dessa realidade e produzir soluçốes. Assim, pode transformá-la e, com seu trabalho, produzir mudanças em si mesmo e no mundo ${ }^{8}$.

Entre os elementos energizadores do movimento pedagógico de ação-reflexão-ação, percebeu-se a importância do conhecimento sobre a realidade. Lembra-nos Freire $^{7}$ que o exercício dialético de refletir e agir fundamenta a educação autêntica, a qual não pode ser concebida fora da práxis, uma vez que compreende os homens nas suas relaçóes com o mundo e entre eles.

Nessa perspectiva, vale ressaltar que a realidade a ser problematizada também contempla o próprio processo ensino-aprendizagem que, ao alinhar a teoria com a prática, também flui em um movimento interdependente de ação-reflexão-ação na (des)construção e na (re) criação das práticas educativas. Sob essa lógica, vimos açôes educativas demandarem novos arranjos temáticos e metodológicos que, por sua vez, exigiram novas práticas e reflexóes.

A presente investigação possibilitou, a partir das especificidades de um lócus de pesquisa isolado - não sendo adequado prender-se ao campo das comparaçóes com outros programas de residências multiprofissionais -, propor reflexóes desenvolvidas em um movimento ajustado de teoria e prática, as quais espera-se serem capazes de gerar açóes em outros cenários reais que, por conseguinte, motivem novas reflexôes promotoras de diferentes estratégias e arranjos necessários para a consolidação da Educação Problematizadora, prevista nas bases pedagógicas das residências multiprofissionais em Saúde ${ }^{14}$, embora suas associações não sejam aprofundadas nos documentos que regem essa modalidade de formação em saúde.

Decerto, uma melhor apropriação dos fundamentos educacionais que sustentam as residências multiprofissionais em Saúde, por parte de tutores, preceptores e residentes, é capaz de potencializar o processo de ensino-aprendizagem para os trabalhadores do SUS. 


\section{Contribuições dos autores}

Maria Clara Santana Maroja e José Jailson de Almeida Júnior participaram da concepção; do delineamento e da redação do trabalho; da discussão dos resultados; da revisão crítica do conteúdo; e da aprovação final da versão do manuscrito.

Claudianny Amorim Noronha participou da redação do trabalho, discussão dos resultados, revisão crítica do conteúdo e aprovação final da versão do manuscrito.

\section{Direitos autorais}

Este artigo está licenciado sob a Licença Internacional Creative Commons 4.0, tipo BY (https://creativecommons.org/licenses/by/4.0/deed.pt_BR).

(cc) BY

\section{Referências}

1. 1. Pasini VL. Residência multiprofissional em saúde: de aventura quixotesca à política de formação de profissionais para o SUS [tese]. Porto Alegre: Pontifícia Universidade Católica do Rio Grande do Sul; 2010.

2. Brasil. Ministério da Saúde. Secretaria de Gestão do Trabalho e da Educação na Saúde. Departamento de Gestão da Educação na Saúde. Residência multiprofissional em saúde: experiências, avanços e desafios. Brasília: Ministério da Saúde; 2006.

3. Brasil. Ministério da Saúde. Secretaria-Executiva. Subsecretaria de Assuntos Administrativos. Educação permanente em saúde: um movimento instituinte de novas práticas no Ministério da Saúde: agenda 2014. Brasília: Ministério da Saúde; 2014.

4. Freire P. Education for critical consciousness. London: Continuum; 2005. p. 3-18.

5. Bardin L. Análise de conteúdo. Lisboa: Edições 70; 2016. p. 125-32.

6. Emmerich AO, Fagundes DQ. Paulo Freire e saúde: revisitando “velhos” escritos para uma saúde do futuro. Saude Transform Soc. 2016; 6(2):1-8.

7. Freire P. Pedagogy of the opressed. London: Continnum; 2005. p. 87-124.

8. Freire P. Educación y cambio. Buenos Aires: Galerna; 2002. p. 3-13.

9. Silva AFG. A construção do currículo na perspectiva popular crítica: das falas significativas às práticas contextualizadas [tese]. São Paulo: Pontifícia Universidade Católica de São Paulo; 2004.

10. Lima JGSA. Considerações críticas sobre interdisciplinaridade: formação de professores para os anos iniciais do ensino fundamental. In: Pernambuco MMCA, Paiva IA, organizadores. Práticas coletivas na escola. Campinas: Mercado de Letras; 2013. p.125-38.

11. Shor I, Freire P. Pedagogy for liberation. London: Bergin \& Garvey Publishers; 1987. p. 51-63.

12. Villardi ML, Cyrino EG, Berbel NAN. A problematização em educação em saúde: percepçóes dos professores tutores e alunos. São Paulo: Cultura Acadêmica; 2015.

13. Alvim NAT, Ferreira MA. Perspectiva problematizadora da educação popular em saúde. Texto Contexto Enferm. 2007; 16(2):315-9. 
14. Brasil. Ministério da Saúde. Secretaria de Gestão do Trabalho e da Educação na Saúde. Departamento de Gestão da Educação na Saúde. Política Nacional de Educação Permanente em Saúde. Brasília: Ministério da Saúde; 2009.

\begin{abstract}
We aim to reflect upon the difficulties and potentials of applying a questioning education in a multiprofessional health residency program to strengthen the Brazilian National Health System (SUS) by qualifying pedagogical actions in this field. This is a participative evaluative research of the case-study type, with a qualitative approach, conducted in a multiprofessional mental health residency program. Among the identified Freire's pedagogical elements, the action-reflection-action feedback loop is highlighted, which enables to intensify the educational process. The limitations of a questioning educational proposal, on the other hand, were related to contradictions with the educational and practical models in health. An improved appropriation of the educational foundations that base multiprofessional health residencies by tutors, preceptors, and residents enables to intensify the teaching and learning process of SUS workers.
\end{abstract}

Keywords: Health professionals education. Questioning. Paulo Freire.

\title{
Resumen
}

Se pretende reflexionar sobre las dificultades y potencialidades en la aplicación de la Educación Problematizadora en un programa de Residencia Multiprofesional en Salud, bajo la perspectiva del fortalecimiento del Sistema Único de Salud, por medio de la calificación de las acciones pedagógicas en ese campo. Se trata de un estudio evaluativo, participativo, con abordaje cualitativo, del tipo Estudio de Caso, realizado en un programa de Residencia Multiprofesional en Salud Mental. Entre los elementos pedagógicos "freireanos” identificados se destaca el ciclo retroalimentado Acción-Reflexión-Acción, capaz de potencializar el propio proceso educacional, mientas que las limitaciones a la propuesta educativa problematizadora se presentaron relacionadas a las contradicciones con los modelos formativos y prácticos vigentes en el campo de la salud. Una mejor apropiación de los fundamentos educativos que sostienen las Residencias Multiprofesionales en Salud, por parte de tutores, preceptores y residentes, es capaz de potencializar el proceso de enseñanza-aprendizaje para los trabajadores del Sistema Único de Salud.

Palabras clave: Formación de profesionales de salud. Problematización. Paulo Freire. 